\title{
CONSERVATIVE TREATMENT VERSUS FIXATION OF TYPE I CORONOID FRACTURE IN TERRIBLE TRIAD INJURIES OF THE ELBOW JOINT
}

\author{
Mohammed Mostafa El-Mahy, Ahmed Naeem Atiyya, Ramy Ahmed Diab, \\ Amr Mostafa Aly and Mohamed Ahmed Abas Mounir Elbishbishi
}

Orthopaedic Department,
Faculty of medicine, Ain Shams
University. Cairo, Egypt
Corresponding:
Mohamed Ahmed Abas Mounir
Elbishbishi,
Mobile : 01003928709
E mail:
mohmouneer@gmail.com
Received: 13/1/2020
Accepted: 12/2/2020

Online ISSN: 2735-3540

\begin{abstract}
:
Background: The coronoid process is considered the keystone of bony elbow stability, in addition to its soft tissue attachment.

Aim of the work: To compare conservative treatment versus fixation of type I coronoid fracture in terrible triad injuries as regard elbow stability, functional outcome, and possible complications.

Patients and methods: We performed a prospective randomized control study on 20 patients with terrible triad injuries and were divided into two equal groups. Randomization was done using Microsoft Excel. Group (1) including 10 patients where the coronoid fracture was not repaired, and Group (2) including 10 patients where the coronoid fracture was repaired. All patients were operated using the lateral approach. In the second group, the coronoid fracture was fixed using pull-out sutures. In both groups, internal fixation was done for the radial head or neck fracture with reattachment of the lateral ulnar collateral ligament (LUCL) to its humeral origin by transosseous sutures. Postoperative patient assessment was done according to the Disabilities of the Arm, Shoulder and Hand (DASH) Score, and the Broberg-Morrey rating system.
\end{abstract}

Results: In the first group, the mean Broberg-Morrey score was 91.2 (range, 85-98) with four excellent results and six good results. The average DASH score was 13 (range, 2.5-30). In the second group, the mean Broberg-Morrey score was 94.4 (range, 89-98) with seven excellent results and three good result. The average DASH score was 9.6 (range, 0-23.3).Two patients experienced postoperative complications in the first group, one implant failure of the radial neck fracture after 3 weeks follow up and the other did not reach complete union of his radial neck. Both patients refused a second operation.

Conclusion: We conclude that fixation of type I coronoid fractures in terrible triad injuries did not show significant difference regarding elbow stability and clinical outcome at short-term follow up.

Keywords: Terrible triad injuries, type I coronoid fractures, coronoid fixation.

\section{INTRODUCTION:}

The term "terrible triad of the elbow" was described by Hotchkiss as a traumatic ulnohumeral dislocation, radial head fracture, and associated coronoid fracture ${ }^{(1)}$. This dislocation pattern and its associated bony fractures earned this nickname due to their historically poor outcomes and the 
possibility for early recurrent dislocation, posttraumatic arthritis, and chronic instability ${ }^{(2)}$.

Usually the traumatic mechanism leading to this injury is a fall onto an outstretched, supinated arm concomitant with a valgus stress through the elbow. This condition accounted $31 \%$ of elbow dislocations in a study by Van Riet and Morrey ${ }^{(3)}$.

Although outcomes have been improved with better understanding of the elbow biomechanics and advancements in implants and surgical techniques, there is no clear agreement that exist concerning how and in which sequence to address repair of the bony and ligamentous injuries. ${ }^{(4)}$

The coronoid process is known as the cornerstone of bony elbow stability, in addition to its soft tissue attachment. ${ }^{(5)}$

The interest in the classification and management of coronoid fractures has increased recently, in part due to better understanding of the role of the coronoid in providing stability to the elbow and improved awareness of its importance. Additionally, more extensive accessibility and use of axial imaging studies has increased our understanding of how these fractures occur and in what patterns. ${ }^{(6)}$

Although coronoid process fractures are seldom isolated; they mostly occur with further elbow injuries as a part of 3 main instability patterns. According to O'Driscoll, Type I fractures are mostly occurring with terrible triad injuries. Type II fractures are frequently seen in association with varus posteromedial rotatory instability. Type III fractures are commonly associated with transolecranon fracture-dislocations. ${ }^{(7)}$

Fixation of the fractured coronoid will aid in stabilizing the elbow; moreover, will avoid its subluxation or dislocation. Furthermore, the fixation technique is unfamiliar to some and difficult to perform making the prerequisite for routine repair of the coronoid debatable. On a retrospective study of 14 terrible triad injuries managed without coronoid repair, Papatheodorou et $\mathrm{al}^{(8)}$ reported that no patient had residual instability with acceptable range of motion, that was counted a good result.

Regrettably, this injury pattern earned its name because of the high possibility for subluxation and dislocation after surgical treatment; therefore, fixation of the coronoid fracture may improve the elbow stability and helps in minimizing these problems. Currently, it is not easy to expect which of these terrible triad injuries will be problematic $^{(9)}$.

Therefore, the following question arises: When treating terrible triad injuries, does coronoid fracture always need to be fixed $?^{(8)}$

\section{AIM OF THE WORK:}

The aim of this work is to compare conservative treatment versus fixation of type I coronoid fracture in terrible triad injuries as regard elbow stability, functional outcome, and possible complications.

\section{PATIENTS AND METHODS:}

After obtaining the hospitals Research/Ethics Committee approval and written informed consents from the patients, this study was carried on 20 Patients with terrible triad injury at Ain Shams university hospitals during the period of August 2017 till August 2019 and were divided into two equal groups, Group (1) including 10 patients where the coronoid fracture was not repaired, and Group (2) including 10 patients where the coronoid fracture was repaired. Randomization was done using Microsoft Excel.

\section{Inclusion criteria:}

- Sex: both sexes.

- Patient with terrible triad injury less than 2 weeks. 
- O’Driscoll type I coronoid fracture.

\section{Exclusion criteria:}

- Patients presented more than 2 weeks.

- O’Driscoll type II\&III coronoid fracture.

- Isolated coronoid fractures.

- Patients with ipsilateral fractures.

The mean follow up of our patients was 18 months (range, 12-24 months). None of the patients were lost in the follow up period. There were 13 males and 7 females with a mean age of 40 years (range, 22-62 years). Seventeen patients had sustained the injury after fall on outstretched hand, and three patients had been injured in road traffic accidents. The dominant arm was affected in 9 patients.

\section{Surgical technique:}

- All patients were operated through the lateral Kocher approach or sometimes, a rent and disruption in the fascia is present forming a plane indicating where to make the interval of dissection.

- Fixation of the bony elements was made from inside-out. In group 2, the coronoid process was repaired by pullout sutures, tightening of sutures was done as the last step after fixation of the radial head and reattachment of the LUCL to avoid stress and looseness of sutures during manipulation.

- In both groups, partial articular radial head fracture was fixed by lag screws. Neck fracture needed plate fixation and in some cases, in addition to the plate, lost wires were also used. Complete radial head fracture required both plate and lag screws with or without lost wires.

- In both groups, re-attachment of the LUCL to its humeral origin was done by transosseous sutures.

- After repair was completed, the elbow stability was checked clinically in full gravity extension in both supination and pronation. Image intensifier was used if needed by checking the A-P and lateral views to evaluate the concentricity of ulnohumeral and radiocapitellar joints, a line drawn through center of radial neck should intersect the center of the capitellum regardless of radiographic projection.

- In our study all patients operated were stable after stability assessment and there was no need to repair the medial collateral ligament.

\section{Postoperative management:}

- The elbow was protected by a posterior splint in $90^{\circ}$ flexion and full pronation for 1 week to decrease stresses on the LUCL repair. The splint was then replaced by hinged elbow brace to allow early active motion in full flexion with extension block in $40-50^{\circ}$. The extension block was decreased weekly by 10 degrees till full extension was attained.

- Physiotherapy could be started after 4-6 weeks to help achieving functional range of motion.

\section{Follow up strategy:}

Patients were followed up in the outpatient clinic at regular intervals for 1 year; weekly for the first 6 weeks, then every 2 weeks in the next 6 weeks, then monthly for 3 months and then after 3 months. This assessment included:

\section{Clinical and functional assessment:}

At the last visit, all patients were assessed according to the Disabilities of the Arm, Shoulder and Hand (DASH) Score ${ }^{(10)}$ and the Broberg-Morrey rating system ${ }^{(11)}$ which is a functional rating system specific to the elbow. A higher score indicates a better functioning elbow. There are a total of 100 points, divided into four categories as follows: motion (40 points), strength (20 points), stability (5 points), and pain (35 
points), with 95-100 points indicating excellent outcome; 80-94 points, good; $60-$
79 points, fair and $<60$ points, poor outcome (table 1).

Table (1): Broberg-Morrey rating system. ${ }^{(11)}$

\begin{tabular}{|c|c|}
\hline Variable & $\begin{array}{l}\text { No. of } \\
\text { points }\end{array}$ \\
\hline Motion (total for each plane) (degrees) & \\
\hline Flexion $(0.2 \times$ arc $)$ & 27 \\
\hline Pronation $(0.1 \times$ arc $)$ & 6 \\
\hline Supination $(0.1 \times$ arc $)$ & 7 \\
\hline \multicolumn{2}{|l|}{ Strength } \\
\hline Normal & 20 \\
\hline $\begin{array}{l}\text { Mild loss (appreciable but not limiting; strength } 80 \% \text { that of } \\
\text { contralateral side) }\end{array}$ & 13 \\
\hline $\begin{array}{l}\text { Moderate loss (limits some activity; strength } 50 \% \text { that of } \\
\text { contralateral side) }\end{array}$ & 5 \\
\hline Severe loss (limits everyday tasks, disabling) & 0 \\
\hline \multicolumn{2}{|l|}{ Stability } \\
\hline Normal & 5 \\
\hline Mild loss (perceived by patient, no limitation) & 4 \\
\hline Moderate loss (limits some activity) & 2 \\
\hline Severe loss (limits everyday tasks) & 0 \\
\hline \multicolumn{2}{|l|}{ Pain } \\
\hline None & 35 \\
\hline Mild (with activity, no medication) & 28 \\
\hline Moderate (with or after activity) & 15 \\
\hline Severe (at rest, constant medication, disabling) & 0 \\
\hline
\end{tabular}

\section{Radiological assessment:}

Which included:

- Plain radiograph.

- CT scan if needed to assess union and stability which was done in 2 patients where the radial neck was fractured to asses union.

\section{RESULTS:}

In the first group, the mean elbow flexion at latest follow up was $133^{\circ}$ (range, $\left.130^{\circ}-140^{\circ}\right)$ and the mean flexion contracture was $18^{\circ}\left(\right.$ range, $0^{\circ}-30^{\circ}$ ) with a mean total arc of $115^{\circ}$ (range, $100^{\circ}-130^{\circ}$ ). The mean forearm pronation was $59^{\circ}$ (range, $50^{\circ}-65^{\circ}$ ) and the mean supination was $72.5^{\circ}$ (range, $50^{\circ}-85^{\circ}$ ) with a mean forearm rotation arc of $131.5^{\circ}$ (range, $105^{\circ}$ $\left.150^{\circ}\right)$. The mean Broberg-Morrey score was 91.2 (range, 85-98) with four excellent results and six good results. The average DASH score was 13 (range, 2.5-30). One patient experienced implant failure and another patient did not reach complete union of his radial neck.

In the second group, the mean elbow flexion was $135^{\circ}$ (range, $130^{\circ}-140^{\circ}$ ) and the mean flexion contracture was $6^{\circ}$ (range, $0^{\circ}-30^{\circ}$ ) with a mean total arc of $129^{\circ}$ (range, $105^{\circ}-140^{\circ}$ ). The mean forearm pronation was $65^{\circ}$ (range, $60^{\circ}-70^{\circ}$ ) and the mean supination was $80^{\circ}$ (range, $75^{\circ}-85^{\circ}$ ) with a mean forearm rotation arc of $145^{\circ}$ (range, $140^{\circ}-155^{\circ}$ ). The mean BrobergMorrey score was 94.4 (range, 89-98) with seven excellent results and three good result. The average DASH score was 9.6 (range, 0-23.3).

As regard the coronoid size (CT-scan based), two patients were classified as O'Driscoll type I a and eighteen patients type Ib. Eight patients had associated radial neck fracture while twelve patients had only radial head fracture. None of the patients had elbow instability after LUCL reattachment. 
Table (2): Comparison between conservative group and fixation group according to DASH score.

\begin{tabular}{|l|c|c|c|c|}
\hline $\begin{array}{l}\text { Postoperative assessment after mean } \\
\text { follow up } 18 \text { months }\end{array}$ & $\begin{array}{c}\text { Conservative } \\
\operatorname{group}(n=10)\end{array}$ & $\begin{array}{c}\text { Fixation } \\
\operatorname{group}(n=10)\end{array}$ & $\mathrm{t} / \mathrm{x} 2 \#$-value \\
\cline { 1 - 3 } DASH score & & & & \\
\hline Mean \pm SD & $13.09 \pm 9.39$ & $9.6 \pm 7.5$ & 0.92 & 0.37 \\
\hline Range & $2.5-30$ & $0-23.3$ & & \\
\hline
\end{tabular}

t- Independent Sample t-test; \#x ${ }^{2}$ : Chi-square test

*p-value $>0.05 \mathrm{NS}$

This table shows no statistically significant difference between conservative

and fixation group according to DASH score.

Table (3): Comparison between conservative group and fixation group according to Broberg-Morrey rating system.

\begin{tabular}{|c|c|c|c|c|}
\hline $\begin{array}{l}\text { Postoperative assessment after mean } \\
\text { follow up } 18 \text { months }\end{array}$ & $\begin{array}{l}\text { Conservative } \\
\text { group }(n=10)\end{array}$ & $\begin{array}{c}\text { Fixation } \\
\operatorname{group}(n=10)\end{array}$ & $\mathrm{t} / \mathrm{x} 2 \#$ & p-value \\
\hline \multicolumn{5}{|l|}{ Broberg-Morrey rating system } \\
\hline Good & $6(60.0 \%)$ & $3(30.0 \%)$ & \multirow[t]{2}{*}{ 1.82\# } & \multirow[t]{2}{*}{0.37} \\
\hline Excellent & $4(40.0 \%)$ & $7(70.0 \%)$ & & \\
\hline \multicolumn{5}{|l|}{ Broberg-Morrey rating system } \\
\hline Mean \pm SD & $91.20 \pm 4.82$ & $94.4 \pm 3.78$ & \multirow[t]{2}{*}{1.68} & \multirow[t]{2}{*}{0.11} \\
\hline Range & $87.5-98$ & $89-98$ & & \\
\hline
\end{tabular}

t-Independent Sample t-test; $\# x^{2}$ : Fisher Exact test

$p$-value $>0.05 \mathrm{NS}$

This table shows no statistically significant difference between both groups according to Broberg-Morrey rating system.

\section{DISCUSSION:}

Due to its close proximity to the neurovascular structures, terrible triad fracture dislocation is considered complex injury, and surgical treatment requires experience. Many surgeons choose the treatment method depending on their experience.

Type I coronoid fractures, concomitant with terrible triad injuries, can usually be treated nonsurgically; however, the optimal treatment remains controversial. O’Driscoll $^{(12,13)}$ and Doornberg and Ring ${ }^{(14)}$ reported that instability of elbow joint could result from a small fracture, such as O'Driscoll type I fractures. These fractures could be more complex than previously thought especially, when associated with lateral collateral ligament or medial

collateral ligament injury, may inevitably lead to elbow instability and may also be ignored by treatment making the outcome more difficult to predict.

The aim of this study is to assess whether the fixation of type I coronoid fractures in terrible triad injuries is necessary to achieve permanent elbow stability in addition to obtain functional and satisfactory outcome; moreover, its importance to avoid possible complications.

In the current study, we performed open reduction and internal fixation through the lateral approach for 20 patients with terrible triad injury.

In the second group, fixation of the coronoid fracture of all the 10 patients was done by pull-out sutures from the lateral approach. Of the 20 patients, there were 12 patients with radial head fracture that requires fixation only by mini screws while 8 patients have associated radial neck fracture that needs plate and screws with or without lost wires, no patient had a radial 
head replacement. The LUCL in all patients was fixed by trans-osseous sutures using 2 tunnels near the isometric point of the lateral epicondyle. There were no intraoperative complications. The average time of the surgery in the 10 patients without fixation of the coronoid was $98.33 \pm 20.00$ minutes and in the 10 patients with fixation of the coronoid was $108.50 \pm 24.95$ minutes. We found that patients with complete radial head fractures were noticed to have longer operative time and this is due to the relative difficulty in obtaining anatomical reduction and the usage of plate and lag screws in their fixation and may be lost wires.

One of our main concerns in this study was reaching the best possible reduction of all elements in the least possible time and also to see if the fixation of the coronoid will make the operation lengthy as we were limited by a tourniquet time. At the end of our study, we reached the repair of the coronoid in about 15-20 minutes. We tried hardly to standardize all methods of fixation between the 2 groups of our study making the coronoid the only variable factor thus having a final accurate results as possible.

In this study, as regard the intraoperative assessment of reduction and joint congruency, all patients had stable congruent joint clinically in full motion arc in supination and pronation as well. Fluoroscopy was used when needed. There was no need for the MCL to be repaired in any patient.

Only 1 patient experienced implant failure of the radial neck fracture after 3 weeks follow up and 1 patient did not reach complete union of his radial neck. Both patients refused a second operation. These 2 patients were in the non-fixed coronoid group. They reached the functional range with mild to moderate pain, which was satisfactory to them as regard their daily activity and work. Further study is needed to determine the relation between the fixation of the coronoid and the radial neck fixation as regard outcomes.

In the non-fixed coronoid group, the mean elbow flexion at latest follow up was $133^{\circ}$ (range, $130^{\circ}-140^{\circ}$ ) and the mean flexion contracture was $18^{\circ}$ (range, $0^{\circ}-30^{\circ}$ ) with a mean total arc of $115^{\circ}$ (range, $100^{\circ}-$ $130^{\circ}$ ). The mean forearm pronation was $59^{\circ}$ (range, $50^{\circ}-65^{\circ}$ ) and the mean supination was $72.5^{\circ}$ (range, $50^{\circ}-85^{\circ}$ ) with a mean forearm rotation arc of $131.5^{\circ}$ (range, $105^{\circ}$ $150^{\circ}$ ). Only one patient obtained more than the functional range of motion.

Papatheodorou et $\mathrm{al}^{(8)}$ reported on a series of 14 terrible triad injuries treated without coronoid repair, the radial head was replaced in 11 patients while fixation was done in only 3 patients with a mean follow up 41 months. The mean elbow flexion was $134^{\circ}$ (range, $95^{\circ}-140^{\circ}$ ) and the mean flexion contracture of $11^{\circ}\left(\right.$ range, $\left.0^{\circ}-20^{\circ}\right)$ with a mean total arc of $123^{\circ}\left(\right.$ range, $\left.75^{\circ}-140^{\circ}\right)$. The mean pronation was $82^{\circ}$ (range, $50^{\circ}-$ $90^{\circ}$ ) with a mean supination of $64^{\circ}$ (range, $\left.20^{\circ}-80^{\circ}\right)$. Their results are comparable to the results in the current study except in pronation because their maximum range limit was $90^{\circ}$ while in our study the maximum range limit was $70^{\circ}$. Furthermore, they performed radial head replacement in 11 patients which is considered a large number that may affect the long term outcome.

In our study, in the fixed coronoid group, the mean elbow flexion was $135^{\circ}$ (range, $130^{\circ}-140^{\circ}$ ) and the mean flexion contracture was $6^{\circ}$ (range, $0^{\circ}-30^{\circ}$ ) with a mean total arc of $129^{\circ}$ (range, $105^{\circ}-140^{\circ}$ ). The mean forearm pronation was $65^{\circ}$ (range, $60^{\circ}-70^{\circ}$ ) and the mean supination was $80^{\circ}$ (range, $75^{\circ}-85^{\circ}$ ) with a mean forearm rotation arc of $145^{\circ}$ (range, $140^{\circ}-$ $155^{\circ}$ ). Seven patients out of 10 have reached more than the functional range of motion which was considered very satisfactory to their daily activity. 
Garrigues et al. ${ }^{(4)}$ reported a retrospective study done on 40 patients with terrible triad injuries with a mean follow up of 18 months. In 28 patients (group1), the coronoid fracture was fixed by pull-out sutures. All coronoid were O'Driscoll type I. The radial head fracture was fixed in 9 patients while radial head arthroplasty was performed in 30 patients without specifying each group. They stated that one patient was lost in the follow up. The mean flexion elbow arc was $136^{\circ}$ with a mean flexion contracture of $18^{\circ}$ and mean total arc was $118^{\circ}$. Seventy five percent of the patients of this study had performed radial head replacement which may influence the long term outcome.

A cohort study by Forthman et al. ${ }^{(15)}$ done on 34 patients where 22 of them had terrible triad injuries with O'Driscoll type I coronoid fractures. Using posterior midline approach in all patients, replacement of all radial head fractures was done except 1 patient underwent fixation, repair of the LUCL, and fixation of all coronoid fractures by sutures except 3 patients were fixed by screws. The mean follow up was 29 months. They noted a mean flexion contracture of $17^{\circ}$, a mean total arc of $117^{\circ}$, and a mean arc of forearm rotation of $137^{\circ}$. They stated that 16 of the 34 patients in this study were overlapped with an investigation that focused on prosthetic arthroplasty of the radial head, which also may affect the long term outcome.

In a retrospective study, Lindenhovius et al. ${ }^{(16)}$ compared the acute treatment of 18 patients with terrible triad injury versus the sub acute treatment ( $>3$ weeks after injury) of 14 terrible triad injuries, all patients were O'Driscoll type I coronoid fractures. Using also, the posterior midline approach in all patients, replacement of all radial head fractures was done except 1 patient underwent fixation, repair of the LUCL, and fixation of all coronoid fractures by sutures except 2 patients were fixed by screws. The mean follow up was 29 months. They noted a mean flexion contracture of $17^{\circ}$, a mean total arc of $119^{\circ}$, and a mean arc of forearm rotation of $141^{\circ}$. They stated that 4 patients had concomitant ipsilateral arm injuries and 5 patients underwent 6 more surgeries which by result may influence the functional outcome.

As regard clinical outcomes, in our first group, the mean Broberg-Morrey score was 91.2 (range, 85-98) with four excellent results and six good results. The average DASH score was 13 (range, 2.5-30). In the second group the mean Broberg-Morrey score was 94.4 (range, 89-98) with seven excellent results and three good result. The average DASH score was 9.6 (range, 023.3). As a result we found that the scores of the first group are nearly same to the previous study in which the coronoid fracture was not repaired, while as regard the second group, our scores are more favorable to those of previous studies in which the coronoid fractures were repaired by pull-out sutures and also to Papatheodorou et $\mathrm{al}^{(8)}$ who reported that unrepaired coronoid has better elbowspecific functional scores.

Compared to our first group, Papatheodorou et $\mathrm{al}^{(8)}$ reported a mean Broberg-Morrey score of 90 with five excellent results, eight good results, and one fair result. The average DASH score was 14.

Compared to our second group, Garrigues et al. ${ }^{(4)}$ reported a mean BrobergMorrey score of 90 including the second group that was fixed by other methods, and without mentioning the number of good or excellent scores. The mean DASH score was 16 .Forthman et al. ${ }^{(15)}$ reported a mean Broberg-Morrey score of 88 with 17 of 22 patients rated good to excellent. Lindenhovius et al. ${ }^{(16)}$ reported mean Broberg-Morrey score for the acute 
treatment group of 90 with 15 of 18 good or excellent. The mean DASH score was 15 .

Recurrent instability was not observed in the current study in both groups. Garrigues et al. ${ }^{(4)}$ found no instability in his first group of patients while 3 patients had instability in the second group where the coronoid was fixed by suture anchor or screw. Forthman et al. ${ }^{(15)}$ noted instability in one patient of his study due to noncompliance.

We assume that the difference noted between the current study and the previous studies regarding the clinical outcome of our second group, may be because they sustained a low energy trauma leading to less soft tissue damage; furthermore, the age group was 6 patients $(60 \%)<40$ years as younger patients are more compliant and motivated to regain more than functional ROM.

One of the limitation in our study is the small number of each group. However, compared to the previous studies, to our knowledge, this is the first comparative randomized prospective study for the meanwhile. Another limitation that may be a cause of the difference between our 2 groups, after analyzing the results, is that three patients $(30 \%)$ of the first group were due to road traffic accident which is considered high energy trauma thus affecting the outcome; moreover, eight patients $(80 \%)$ of this group had associated radial neck fracture and underwent fixation increasing the possibility of fracture nonunion, and implant failure or irritation.

\section{Conclusion:}

According to this work, we conclude that fixation of type I coronoid fractures in terrible triad injuries did not show significant difference regarding elbow stability and clinical outcome at short-term follow up.

\section{REFERENCES:}

1. Hotchkiss RN. Fractures and dislocations of the elbow. In: Rockwood CA Jr, Green DP, Bucholz RW, etal., eds. Rockwood and Green's Fractures in Adults, Vol. 1, 4th ed. Philadelphia, PA: Lippincott Raven, 1996; 929-1024.

2. Chen NC, Ring D. Terrible triad injuries of the elbow. J Hand Surg Am. 2015; 40(11): 2297-303.

3. Van Riet RP, Morrey BF. Documentation of associated injuries occurring with radial head fracture. ClinOrthopRelat Res. 2008; 466 (1): 30-134.

4. Garrigues GE, Wray WH III, Lindenhovius ALC, Ring DC, Ruch DS. Fixation of the coronoid process in elbow fracturedislocations. J Bone Joint Surg Am. 2011; 93 (20):1873-1881.

5. Chemama B, Bonnevialle $\mathrm{N}$, Peter $\mathrm{O}$, Mansat P, Bonnevialle P. Terrible triad injury of the elbow: how to improve outcomes? OrthopTraumatolSurg Res 2010; 96:147-54.

6. Adams JE, Sanchez-Sotelo J, Kallina IV CF, Morrey BF, Steinmann SP. Fractures of the coronoid: morphology based upon computed tomography scanning. J Shoulder Elbow Surg 2012 Jun; 21: 782-8

7. Jeffrey E. Budoff, MD, Coronoid Fractures, J Hand Surg 2012; 37A:2418-2423.

8. Papatheodorou LK, Rubright JH, HeimKA, Weiser RW, Sotereanos DG. Terrible triad injuries of the elbow: does the coronoid always need to be fixed? ClinOrthopRelat Res. 2014; 472(7):2084-2091.

9. Gupta A, Barei D, Khwaja A, Beingessner D. Single-staged treatment using a standardized protocol results in functional motion in the majority of patients with a terrible triad elbow injury. ClinOrthopRelat Res. 2014; 472(7):2075-2083.

10. Hudak PL, Amadio PC, Bombardier C. Development of an upper extremity outcome measure: the DASH (Disabilities of the Arm, Shoulder and Hand). The Upper 
Extremity Collaborative Group (UECG). Am J Ind Med. 1996;29:602-608.

11. Broberg MA, Morrey BF.Results of delayed excision of the radial head after fracture. $\mathrm{J}$ Bone Joint Surg Am. 1986;68:669-674.

12. O'Driscoll SW, Jupiter JB, Cohen MS, Ring D, McKee MD: Difficult elbow fractures: Pearls and pitfalls. Instr Course Lect 2003;52:113-134.

13. O'Driscoll SW, Bell DF, Morrey BF: Posterolateral rotatory instability of the elbow. J Bone Joint Surg Am 1991; 73:440446.
14. Doornberg JN, Ring D. Coronoid fracture patterns. J Hand Surg Am. 2006; 31(1):4552.

15. Forthman C, Henket M, Ring DC: Elbow dislocation with intra-articular fracture: The results of operative treatment without repair of the medial collateral ligament. J Hand Surg Am. 2007; 32:1200-1209.

16. Lindenhovius AL, Jupiter JB, Ring D. Comparison of acute versus subacute treatment of terrible triad injuries of the elbow. J Hand Surg Am. 2008 ;33:920-926. 


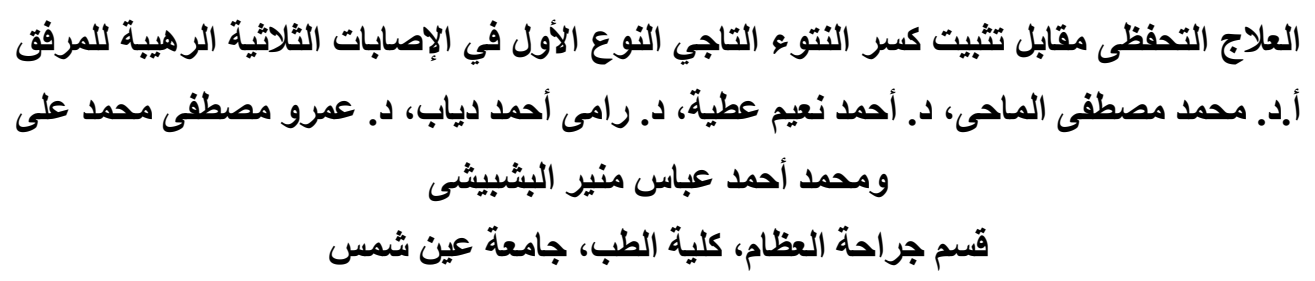

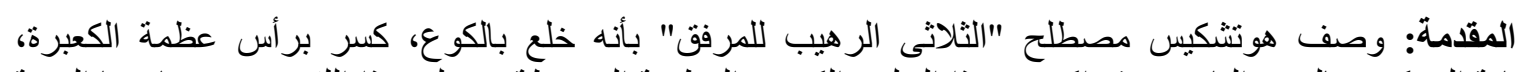

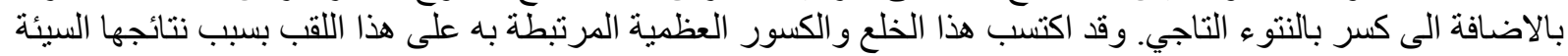

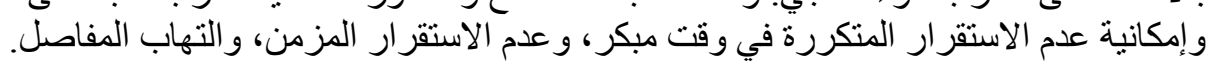

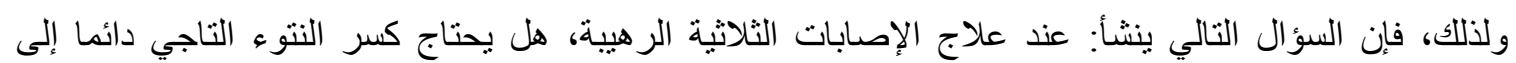
التثبيت؟ الهُف من الاراسة: مقارنة العلاج التحفظى مقابل تثبيث كسر النتوء التاجي النوع الأول في الإصابات الثناثية

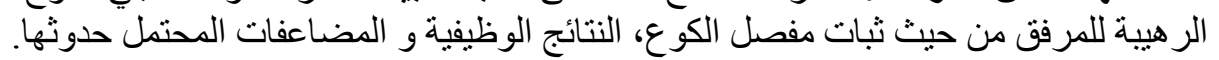

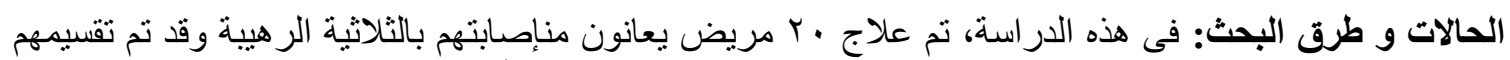

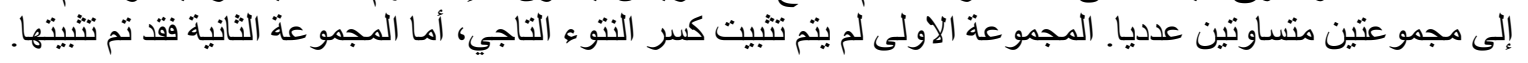

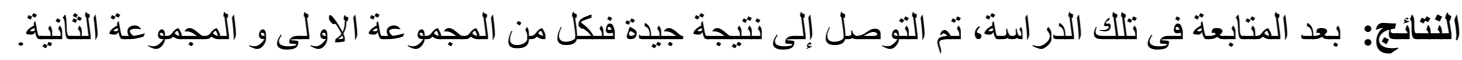
خلاصة البحث: لذللك توصلنا إلى أنه ليس هناك فارق كبير بين تثبيت كسر النتوء التاجي المصاحب للتبدة للإصابات الثلاثية الرهيبة من عدم تثبيته. 